\section{GRAPHIC DETAIL Securing UK science}

British politicians have given no assurances that science will be protected from the deep cuts in public spending that are predicted to follow this year's general election (see Nature 463, 410-411; 2010). But Britain's Royal Society is trying to ward off the expected blow. In a report entitled The Scientific Century: Securing Our Future Prosperity, released on 9 March, the venerable society argues that slashing support for research would be a false economy, and would harm the nation's long-term economic prospects.

The United Kingdom has traditionally punched above its weight in science, garnering a

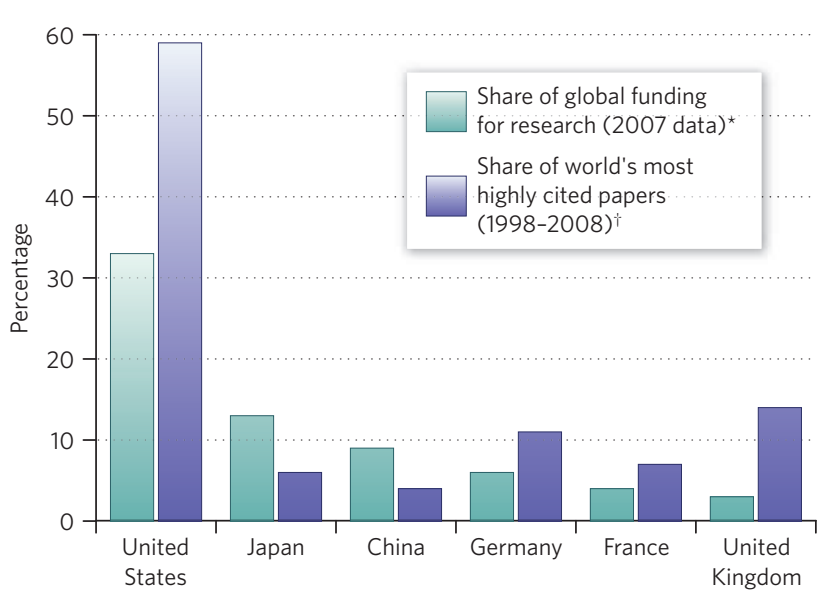

bigger proportion of the most highly cited research papers than its share of global funding would suggest (see graphic). But this impressive track record is "fragile" and brings a "risk of complacency", the report says, noting competition from rising research funding in India, China and Brazil, along with significant investment for science seen in the stimulus packages in the United States, France and Germany.

The dossier models itself on Rising Above the Gathering Storm, an influential 2005 report by the US National Academies that advocated increased funding to maintain America's pre-eminent position in science. The Royal Society argues along similar lines: "Our scientific leadership, which has taken decades to build, can quickly be lost," it warns.

The report asks the UK government to outline plans for increased research funding over a 15-year period (2011-26). It also recommends expanding a tax credit for research and development to stimulate investment by businesses, and outlines the need for policies that encourage researchers from overseas to work in the country.

Richard Van Noorden

http://royalsociety.org/ the-scientific-century

\title{
A rescue plan for UK physics funding
}

Britain's most troubled research council is about to undergo radical surgery. On 4 March, UK science minister Paul Drayson unveiled his plan to reform the Science and Technology Facilities Council (STFC), the main research council that provides funding for particle physics, space science, nuclear physics and astronomy.

The plan, which promises to end years of financial turbulence for the council, has gained tentative support from the physics community, which had previously been incensed over repeated budget shortfalls that forced the STFC to slash grants and cut operations (see Nature 462, 396; 2009).

"We're very pleased," says Robert KirbyHarris, chief executive of the London-based Institute of Physics, which represents the country's physicists. But missing from the plan is more money for research funding. Grants will still be cut back, and Britain still plans to withdraw from the multinational Gemini telescope project in 2012.

The STFC was formed in 2007 by merging two councils: one that managed large facilities and another that disbursed physics and astronomy grants. Almost immediately it became clear that the organization faced an $£ 80$-million (US\$121-million) shortfall, leading to drastic cuts. But this year it has again come up short, by $\mathfrak{E 4 0}$ million. "That was leading to damage on the grants end of its responsibilities," says Drayson.

Drayson set up a ministerial commission to look into what he describes as the "tough problem" of balancing the STFC's commitments and grants, resulting in a proposed three-part reform. First, the council will keep the running costs for its large facilities separate from grant funding and budget them over a six-year period. Second, it will enlist the Bank of England to help it manage the cost of overseas subscriptions to institutions such

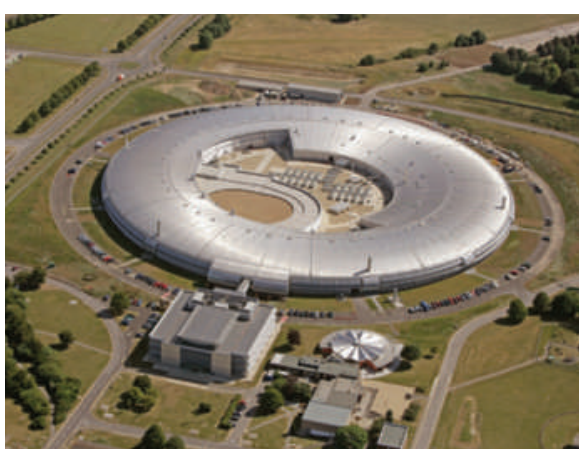

New proposals could safeguard funding for big UK facilities such as the Diamond Light Source. as the European Southern Observatory, headquartered in Garching, Germany, and CERN, Europe's particle-physics laboratory near Geneva, Switzerland, in order to minimize the impact of the pound's poor exchange rate. Third, the UK subscription to the European Space Agency (ESA), the STFC's most costly international commitment, will be moved to a new British space agency that is scheduled to be launched later this month.

The plan "is just good business sense", says Kirby-Harris. By making sure that the STFC's fixed costs are appropriately budgeted, the council should be able to better serve the physicists and astronomers who depend on it for grants, he says. Moving the ESA subscription to the new space agency makes sense, adds Andrew Fabian, president of the Royal Astronomical Society in London, although the implications of this move for astronomers are not yet clear.

The proposed changes should happen after the government's next spending review, which is currently scheduled to follow a national election that is expected to be called in May. Any change of government could yet upend the plan. Geoff Brumfiel 